\title{
A novel use for novel acute kidney injury biomarkers: fenoldopam's effect on neutrophil gelatinase-associated lipocalin and cystatin C
}

\author{
Stuart L Goldstein* \\ See related research by Ricci et al., http://ccforum.com/content/15/3/R160
}

\begin{abstract}
Substantial basic and translational research has been directed to detect earlier and more sensitive acute kidney injury (AKI) biomarkers over the past decade. Much of the seminal AKI biomarker validation research has been performed in children undergoing cardiopulmonary bypass since they represent an ideal clinical model for AKI biomarker study: the timing of the injury is known and children do not have many of the co-morbidities seen in adult patient populations, which can confound the clinical situation. Ricci and colleagues report the results of their study using two novel urinary AKI biomarkers, neutrophil gelatinaseassociated lipocalin (NGAL) and cystatin C - not to predict $\mathrm{AKI}$, but to define it - in a randomized trial of intraoperative fenoldopam to prevent AKI. They demonstrate that fenoldopam administration led to decreased postoperative urine NGAL and urine cystatin C concentrations, suggesting a renoprotective effect. Given the high sensitivity of NGAL for AKI post cardiopulmonary bypass, this study provides a model to use novel AKI biomarkers in a novel manner.
\end{abstract}

The past decade of clinical and translational acute kidney injury (AKI) research has focused on the validation of novel biomarkers to detect AKI earlier, to ultimately provide researchers and clinicians with a much soughtafter golden window of opportunity to prevent AKI development or mitigate its course. In the current study, Ricci and colleagues take the next logical step to use two novel biomarkers, neutrophil gelatinase-associated lipocalin

*Correspondence: stuart.goldstein@cchmc.org

Cincinnati Children's Hospital Medical Center, 3333 Burnet Avenue, MLC 7022, Cincinnati, OH 45206, USA
(NGAL) and cystatin $\mathrm{C}$, in a novel manner to define AKI rather than predict AKI [1]. In their randomized trial, the investigators demonstrate the $\alpha_{1}$-selective dopamine agonist fenoldopam to be associated with lower postoperative urinary NGAL and cystatin C concentrations compared with placebo. Furthermore, fenoldopam-treated children had a lower rate of reaching a urinary NGAL threshold of $200 \mathrm{ng} / \mathrm{ml}$, suggesting its renoprotective effects, despite no differences in creatinine-associated AKI development by the pediatric RIFLE criteria [2].

Children undergoing bypass represent an ideal model for AKI biomarker study since the timing of the kidney injury is known, interventions can be planned ahead of time, and children do not have many of the comorbidities of adulthood that can complicate studies $[3,4]$. Previous trials of fenoldopam in children and adults to prevent serum-creatinine-defined AKI have had mixed results [5-8], with pediatric observational studies showing a benefit in terms of enhanced urine output postoperatively. The chronological paradigm shift evaluating intraoperative agent administration to detect its effect on an early and sensitive marker of AKI such as NGAL provides a model for future randomized trials in this field.

Importantly, the recent pooled analysis of 10 pediatric and adult studies by Haase and colleagues showing that 'NGAL-positive, serum creatinine-negative AKI' was associated with equivalent or worse outcomes compared with 'creatinine-positive, NGAL-negative AKI' [9] provides strong support for Ricci and colleagues' decision to use NGAL to define AKI. In fact, Haase and colleagues comment that in the absence of diagnostic increases in serum creatinine, NGAL detects patients with likely subclinical AKI who have an increased risk of adverse outcomes. The concept and definition of AKI might need re-assessment' [9]. In addition, patients treated with fenoldopam required fewer diuretics and vasodilators, demonstrating a clinically observable clinical benefit of fenoldopam associated with the reduction in biomarker concentrations. 
For the past decade, the assault on serum creatinine as an AKI biomarker has been relentless, with good reason, as adults and children with small rises in serum creatinine have increased risk of mortality and morbidity [10-12], and we have recognized that patients are dying from AKI and not just dying with AKI [13]. The search for the renal troponin I or the renal brain natriuretic peptide has also led to the development of the concept of renal angina to identify patients at risk for AKI and to rule out patients not at risk who do not full the renal angina criteria [14]. Use of new biomarkers to define AKI, or perhaps in future studies to enrich study populations to assess the effects of interventions on reducing AKI development and/or severity, has been the holy grail for AKI researchers to improve outcomes in critically ill patients at risk for AKI, or with AKI. Ricci and colleagues have, for possibly the first time, connected the clinical and research sides of the translational research bridge with their current study. While future studies will need to confirm their findings in larger more complex cohorts, their work has brought AKI study out of the past and into an exciting present and future.

\section{Abbreviations}

AKI, acute kidney injury; NGAL, neutrophil gelatinase-associated lipocalin; RIFLE, Risk, Injury, Failure, Loss and End-stage.

\section{Competing interests}

The author declares that he has no competing interests.

Published: 2 August 2011

\section{References}

1. Ricci Z, Luciano R, Favia I, Garisto C, Muraca M, Morelli S, Di Chiara L, Cogo P, Picardo S: High-dose fenoldopam reduces post operative neutrophil gelatinase associated lipocaline and cystatin C levels in pediatric cardiac surgery. Crit Care 2011, 15:R160.

2. Akcan-Arikan A, Zappitelli M, Loftis LL, Washburn KK, Jefferson LS, Goldstein SL: Modified RIFLE criteria in critically ill children with acute kidney injury. Kidney Int 2007, 71:1028-1035.
3. Krawczeski CD, Woo JG, Wang Y, Bennett MR, Ma Q, Devarajan P: Neutrophil gelatinase-associated lipocalin concentrations predict development of acute kidney injury in neonates and children after cardiopulmonary bypass. J Pediatr 2011, 158:1009-1015.

4. Mishra J, Dent C, Tarabishi R, Mitsnefes MM, Ma Q, Kelly C, Ruff SM, Zahedi K, Shao M, Bean J, Mori K, Barasch J, Devarajan P: Neutrophil gelatinaseassociated lipocalin (NGAL) as a biomarker for acute renal injury after cardiac surgery. Lancet 2005, 365:1231-1238.

5. Bove T, Landoni G, Calabro MG, Aletti G, Marino G, Cerchierini E, Crescenzi G, Zangrillo A: Renoprotective action of fenoldopam in high-risk patients undergoing cardiac surgery: a prospective, double-blind, randomized clinical trial. Circulation 2005, 111:3230-3235.

6. Costello JM, Thiagarajan RR, Dionne RE, Allan CK, Booth KL, Burmester M, Wessel DL, Laussen PC: Initial experience with fenoldopam after cardiac surgery in neonates with an insufficient response to conventional diuretics. Pediatr Crit Care Med 2006, 7:28-33.

7. Moffett BS, Mott AR, Nelson DP, Goldstein SL, Jefferies JL: Renal effects of fenoldopam in critically ill pediatric patients: a retrospective review. Pediatr Crit Care Med 2008, 9:403-406.

8. Tumlin JA, Finkel KW, Murray PT, Samuels J, Cotsonis G, Shaw AD: Fenoldopam mesylate in early acute tubular necrosis: a randomized, double-blind, placebo-controlled clinical trial. Am J Kidney Dis 2005 , 46:26-34.

9. Haase M, Devarajan P, Haase-Fielitz A, Bellomo R, Cruz DN, Wagener G, Krawczeski CD, Koyner JL, Murray P, Zappitelli M, Goldstein SL, Makris K, Ronco C, Martensson J, Martling CR, Venge P, Siew E, Ware LB, Ikizler TA, Mertens PR: The outcome of neutrophil gelatinase-associated lipocalinpositive subclinical acute kidney injury a multicenter pooled analysis of prospective studies. J Am Coll Cardio/ 2011, 57:1752-1761.

10. Srisawat N, Hoste EE, Kellum JA: Modern classification of acute kidney injury. Blood Purif 2010, 29:300-307.

11. Chertow GM, Burdick E, Honour M, Bonventre JV, Bates DW: Acute kidney injury, mortality, length of stay, and costs in hospitalized patients. J Am Soc Nephrol 2005, 16:3365-3370.

12. Price JF, Mott AR, Dickerson HA, Jefferies JL, Nelson DP, Chang AC, O'Brian Smith E, Towbin JA, Dreyer WJ, Denfield SW, Goldstein SL: Worsening renal function in children hospitalized with decompensated heart failure: evidence for a pediatric cardiorenal syndrome? Pediatr Crit Care Med 2008, 9:279-284.

13. Kellum JA, Angus DC: Patients are dying of acute renal failure. Crit Care Med 2002, 30:2156-2157.

14. Goldstein SL, Chawla LS: Renal angina. Clin J Am Soc Nephrol 2010, 5:943-949.

doi:10.1186/cc10296

Cite this article as: Goldstein SL: A novel use for novel acute kidney injury biomarkers: fenoldopam's effect on neutrophil gelatinase-associated lipocalin and cystatin C. Critical Care 2011, 15:177. 